\title{
Effects of Reducing PbO Content on the Elastic and Radiation Attenuation Properties of Germanate Glasses: A New Non-toxic Candidate for Shielding Applications
}

\section{M.S. Al- Buriahi ( $\nabla$ mohammed.al-buriahi@ogr.sakarya.edu.tr)}

Sakarya Universitesi https://orcid.org/0000-0001-9750-072X

\section{I.O. Olarinoye}

Federal Technological University of Paraná - Medianeira Campus: Universidade Tecnologica Federal do Parana - Campus Medianeira

\section{Mutuwong}

Ubon Ratchathani University

\section{H. I. Elsaeedy}

King Khalid University

\section{Barış Tamer Tonguç}

Sakarya University: Sakarya Universitesi

\section{Research Article}

Keywords: Germanate glass, Elastic moduli, Shielding, Radiation, Geant4 simulation

Posted Date: March 4th, 2021

DOl: https://doi.org/10.21203/rs.3.rs-264843/v1

License: (c) (i) This work is licensed under a Creative Commons Attribution 4.0 International License.

Read Full License 


\title{
Effects of reducing $\mathrm{PbO}$ content on the elastic and radiation attenuation properties of germanate glasses: A new non-toxic candidate for shielding applications
}

\author{
M.S. Al-Buriahi ${ }^{1}$, I.O. Olarinoye ${ }^{2}$, C. Mutuwong ${ }^{3}$, H. I. Elsaeedy ${ }^{4}$, Barış Tamer Tonguç ${ }^{1}$ \\ ${ }^{1}$ Department of Physics, Sakarya University, Sakarya, Turkey \\ ${ }^{2}$ Department of Physics, School of Physical Sciences, Federal University of Technology, Minna, Nigeria \\ ${ }^{3}$ Department of Physics, Ubon Ratchathani University, Ubon Ratchathani, Thailand \\ ${ }^{4}$ Department of Physics, Faculty of Science, King Khalid University, P.O. Box 9004, Abha; Saudi Arabia
}

\section{Abstract}

This work presents a detailed study on the effects of reducing $\mathrm{PbO}$ content on the elastic and radiation shielding properties of germanate glasses described by the chemical formula $50 \mathrm{GeO}_{2}$ (50-x)PbO-xZnO, where $\mathrm{x}$ between 0 and $50 \mathrm{~mol} \%$ with step of 10 . A theoretical analysis based on Makishima-Mackenzie's theory (MM-theory) was employed to obtain the elastic moduli of the studied glass specimens. Moreover, the Monte Carlo simulations were applied via Geant4 platform to assess the radiation shielding ability of the $\mathrm{GeO}_{2}-\mathrm{PbO}-\mathrm{ZnO}$ glass system by evaluating several fundamental properties such as gamma and neutron transmission factors, total cross sections, effective atomic numbers, 1/e penetration depths, and exposure buildup factors. We found that the bulk elastic modulus increased from $50.751 \mathrm{GPa}$ to $85.389 \mathrm{GPa}$ as the $\mathrm{PbO}$ content increased from $50 \mathrm{~mol} \%$ to 0 . The results of the linear attenuation coefficient show that the cross sections of $(\sigma)_{P E},(\sigma)_{C S}$, and $(\sigma)_{P P}$ dominates the photon attenuation at $0.15 \leq \mathrm{E} \leq 0.08 ; 0.8<\mathrm{E}<8$, and 8 $<\mathrm{E}<15 \mathrm{MeV}$ respectively. Moreover, the present glasses have superior photon absorbing capacity compared to ordinary and barite concrete; RS-253-G18 and RS-360 commercial glass shields. This 
suggests that the $\mathrm{GeO} 2-\mathrm{PbO}-\mathrm{ZnO}$ glass system can be used as a non-toxic shielding material in the nuclear facilities.

Keywords: Germanate glass; Elastic moduli; Shielding; Radiation; Geant4 simulation.

\section{*Corresponding author: mohammed.al-buriahi@ogr.sakarya.edu.tr}

\section{Introduction}

Nuclear radiation has become an essential tool in many applications to ensure the high quality of our daily lives. For examples, nuclear radiation plays a main role in medicine for diagnostic and treatment complicated diseases such as cancer [1]. Moreover, radiation (e.g. x-rays) is used in security devices to detect weapons in luggage as well as to warn us of fire (smoke detectors) [2]. However, there are catastrophic health risks associated with frequently exposure to nuclear radiation [3-5]. Therefore, the radiation shielding is a considerable technology in the nuclear facilities to protect the workers and public from exposure to the damaging radiation [6, 7]. Over the years, lead $(\mathrm{Pb})$ and its products are used as reliable shielding materials due to their scientifically known ability to block radiation [8-11]. Nevertheless, there are also serious concerns related to the toxicity of $\mathrm{Pb}$ and its harmful effects on human and environment [12-14].

At present, several glass systems are being considered as advanced radiation shielding technologies in dental and medical applications. Stalin et al. reported on a new LBWB glass system containing $\mathrm{Bi}_{2} \mathrm{O}_{3}$ as a heavy metal oxide to modify the shielding ability of the system [15]. The highest density was recorded for the LBWB0 sample with the value of $3.969 \mathrm{~g} / \mathrm{cm}^{3}$. Moreover, the best shielding ability was also for the LBWB0 sample with the mass attenuation value of 69.367 $\mathrm{cm}^{2} / \mathrm{g}$ at the low energy region $(15 \mathrm{keV})$. Boukhris et al. investigated the impact of $\mathrm{PbO}$ addition 
on the optical features and gamma shielding efficiency of four glass samples containing $\mathrm{Na}_{2} \mathrm{O}$, $\mathrm{Sb}_{2} \mathrm{O}_{3}, \mathrm{WO}_{3}$, and $\mathrm{PbO}[16]$. The obtained results show that the highest optical transmission was recorded for $\mathrm{SbNaWPb} 1$ sample (lowest $\mathrm{PbO}$ content) with the value 0.7916 , and the maximum of the mass attenuation coefficient (MAC) is found at $0.284 \mathrm{MeV}$ with the value of $0.2750 \mathrm{~cm}^{2} / \mathrm{g}$ for the $\mathrm{SbNaWPb} 4$ sample (highest $\mathrm{PbO}$ content). Olarinoye et al. studied the impact of $\mathrm{La}_{2} \mathrm{O}_{3}$ content on the mechanical features (elastic moduli) and radiation shielding ability of $\mathrm{ZnO}$-based glasses [17]. The bulk modulus and the other elastic moduli were found in a decrease trend as the $\mathrm{La}_{2} \mathrm{O}_{3}$ content increased up to $10 \mathrm{~mol} \%$. Moreover, the maximum MAC occurred at $15 \mathrm{keV}$ with the value of $43.019 \mathrm{~cm}^{2} \mathrm{~g}^{-1}$ for LZB4 sample (highest $\mathrm{La}_{2} \mathrm{O}_{3}$ content). Recently, germanate glass systems attract a tremendous scientific attention due to their unique physical, optical, and structural properties [18-21]. For example, these glass systems have high solubility, high density, low melting points, wide light transmittance, high immunity, and high refractive indices [19-22]. Such promising properties of germanate glass systems encouraged us to investigate their fundamental radiation shielding features.

In the present research article, the effects of reducing $\mathrm{PbO}$ content on the elastic and radiation shielding properties of the $\mathrm{GeO}_{2}-\mathrm{PbO}-\mathrm{ZnO}$ glass system. A theoretical analysis based on MMtheory was employed to obtain the elastic moduli of the studied glass specimens. Furthermore, the Monte Carlo simulation was applied via Geant4 platform to assess the radiation shielding ability of the $\mathrm{GeO}_{2}-\mathrm{PbO}-\mathrm{ZnO}$ glass system by evaluating several fundamental properties such as gamma and neutron transmission factors, total cross sections, effective atomic numbers, 1/e penetration depths, and exposure buildup factors. 


\section{Materials and methods}

\subsection{Glass preparation}

The glass specimens described by the chemical form of $50 \mathrm{GeO}_{2}-(50-\mathrm{x}) \mathrm{PbO}-\mathrm{xZnO}$, where $\mathrm{x}$ between 0 and 50 mol \% with step of 10 , were prepared by melting the amounts of $\mathrm{GeO}_{2}, \mathrm{PbO}$, and $\mathrm{ZnO}$ at temperature of $1000-1560{ }^{\circ} \mathrm{C}$, as reported in Ref. [23]. The detailed chemical constituent and density for each studied glass samples can be found in Table 1.

\subsection{Theoretical analysis}

A theoretical analysis based on Makishima-Mackenzie's theory (MM-theory) was employed to obtain the elastic moduli of the studied glass specimens. The full description of MM-theory can be found in Refs $[25,26]$. Briefly, it depends on some compositional factors such as $\mathrm{M}_{\mathrm{w}}$ and $\mathrm{V}_{\mathrm{m}}$ and several parameters like packing factor $\left(V_{t}\right)$ and dissociation energy $\left(G_{t}\right)$. All the mathematical relations of MM-theory are summarized in Table 2. More details about the elastic properties of different glass systems are reported by El-Moneim et al. [27-29].

On the hand, the theoretical analysis of the radiation shielding study was employed by using Phy$\mathrm{X}$ software over a wide energy range varying between $15 \mathrm{keV}$ and $15 \mathrm{MeV}$ [30]. This software offers more than 15 parameters to investigate the radiation shielding competence of any composite materials.

\subsection{Simulation method}

Monte Carlo is a promising method to deal with the scientific problems in the software environment by eliminating all the difficulties of experiments like the high cost and exposure risks in radiation studies. By applying Monte Carlo method, several simulations were carried out by 
using Geant4 toolkit over a wide energy range reaching $15 \mathrm{MeV}$ [24]. The present simulation geometry contains a vacuum system as a main part where all the simulation setup was placed there. Such that gamma source, sample, and the detector were placed in the designed vacuum system, as shown in Fig. 1.

\section{Results and discussion}

Table 3 summarizes the elastic features such as packing density (or packing factor), dissociation energy, and the four elastic moduli $\left(\mathrm{E}_{\mathrm{th}}, \mathrm{K}_{\mathrm{th}}, \mathrm{S}_{\mathrm{th}}\right.$, and $\left.\mathrm{L}_{\mathrm{th}}\right)$ of the present $\mathrm{GeO}_{2}-\mathrm{PbO}-\mathrm{ZnO}$ glass samples. From this table, it is clear that all the elastic features strongly relate with the glass composition. Such that the molar volume (see Table 1) of the present glasses is similar to the behavior for the density. With reducing $\mathrm{PbO}$ content from $50 \mathrm{~mol} \%$ to 0 , the molar volume decreased from 30.129 to 20.575 , and all of $\mathrm{E}_{\mathrm{th}}, \mathrm{K}_{\mathrm{th}}, \mathrm{S}_{\mathrm{th}}$, and $\mathrm{L}_{\mathrm{th}}$ increased from 101.857 to 149.797 , from 50.751 to 85.389 , from 46.865 to 66.351 , and from 113.238 to 173.857 for $\mathrm{E}_{\text {th }}, \mathrm{K}_{\mathrm{th}}, \mathrm{S}_{\mathrm{th}}$, and $\mathrm{L}_{\text {th }}$, respectively. Therefore, the interesting observation is that the elastic moduli of pure $\mathrm{GeO}_{2}$ $\mathrm{ZnO}$ (G50 glass sample with the lowest density) are much greater than those of pure $\mathrm{GeO}_{2}-\mathrm{PbO}$ (G00 glass sample with the highest density). The obtained results are attributed to the structural role of $\mathrm{PbO}$ and $\mathrm{ZnO}$ in the germanate glasses network [27-29].

Photon transmission $(\mathrm{T})$ in the narrow beam approximation is predicted by the Beer-Lambert equation: $T=I / I_{o}=e^{-\mu t}$. The linear attenuation coefficient $(\mu)$ of a photon absorbing medium can be obtained via the transmission experiment or simulation using the equation. Using the Geant4 simulation tool and Phy-X free web-based software, $\mu$ was obtained for the glasses for photon energies (E) in the range $0.015 \leq \mathrm{E} \leq 15 \mathrm{MeV}$ and presented in Table 4 and Table 5. Also, 
presented in the tables is the deviation (Dev. in \%) between the $\mu$ value obtained via the two methods. The Dev. is calculated according to the expression [31, 32]:

$$
\text { Dev. }(\%)=\left|\left[(\mu)_{X C O M}-(\mu)_{\text {Geant } 4}\right] \div(\mu)_{X \operatorname{COM}}\right| \times 100
$$

Values of $\mu$ presented in Tables $4 \& 5$ show that the simulation results agree well with the direct calculation with Phy-X tool. Quantitatively, the agreement is showcased in the value of Dev. which varies between $0.50-1.54,0.55-1.86,0.51-1.96,0.52-1.86,0.63-1.73$, and $0.63-1.94 \%$ for G00 - G50 respectively. Clearly the simulation result is reliable and accurate. Generally, $\mu$ decreases in value with photon energy for all the glasses, hence, the maximum value was obtained at the least energy while the least $\mu$ value was gotten between 6 and $8 \mathrm{MeV}$ depending on the chemical content of the glasses. For the energy range given in the table, three basic photon interaction processes and their gross section dictate the value $\mu$ and its variation with $\mathrm{E}$. These are photoelectric effect (PE), Compton scattering (CS), and pair production (PP) absorption processes. Their respective cross section $(\sigma)$ depends on $\mathrm{E}$ according to: $(\sigma)_{P E} \propto E^{-3.5},(\sigma)_{C S} \propto E^{-1}$, and $(\sigma)_{P P} \propto E$. The result of the linear attenuation coefficient of the glasses as presented in Table 2 shows that $(\sigma)_{P E},(\sigma)_{C S}$, and $(\sigma)_{P P}$ dominates the photon interaction cross section at $0.15 \leq \mathrm{E} \leq$ $0.08 ; 0.8<\mathrm{E}<8$, and $8<\mathrm{E}<15 \mathrm{MeV}$ respectively. Also, the $\mu$ data revealed that $(\sigma)_{P E},(\sigma)_{C S}$, and $(\sigma)_{P P}$ is maximum at $15 \mathrm{keV}, 6-8 \mathrm{MeV}$ and $15 \mathrm{MeV}$ in the glasses respectively. The position of the peak of $(\sigma)_{C S}$ changes as the atomic number of the glasses changes [31]. Hence, minimum $\mu$ value was obtained at different energies depending on the glass' effective atomic number.

In order to clearly present the variation of photon attenuation capacity of the G00 - G50 glasses with respect to photon energy and chemical content, the mass attenuation coefficient $(\mu / \rho)$ at 
selected energies $(0.015,0.03,0.05,0.1,0.2,0.5,1$, and $2 \mathrm{MeV})$ is presented in Figure 2. According to the figure $\mu / \rho$ diminishes with $\mathrm{E}$ in a similar way as $\mu$. The gradual decline of $\mu / \rho$ is due to the decay in photon interaction cross section as photon energy grows. Furthermore, at equal energy, ${ }^{\mu} / \rho$ increases as $\mathrm{PbO}(\mathrm{ZnO})$ molar concentration in the glasses grows (declines). Thus, G00 with maximum $\mathrm{PbO}$ concentration produced the highest $\mu / \rho$ throughout the energy spectrum. This trend can be attributed to the relative higher atomic number, density, and hence photon absorption cross section of $\mathrm{Pb} / \mathrm{PbO}$ compared to other chemical species in the glass system. This also explains the increase in the mass density of the glasses as $\mathrm{PbO}$ increases.

The effect of the glasses' composition on photon absorption competence may be quantitatively assessed and compared via the effective atomic number, $Z_{\text {eff }}$. The variation of $Z_{e f f}$ with $\mathrm{E}$ is presented in Figure 3. The value of $Z_{\text {eff }}$ initially increases with $\mathrm{E}$ and latter declines at $\mathrm{E}>0.1$ $\mathrm{MeV}$ for G00-G40, while for G50, the effective atomic number declines continuously with photon energy. The initial increase observed for G00 - G40 is attributed to an increase in photon absorption at the $\mathrm{K}$-absorption edge of $\mathrm{Pb}$, hence, the growth of $Z_{\text {eff }}$ peak around the $\mathrm{Pb} \mathrm{K}-$ absorption edge. Also, it is obvious that the value of $Z_{\text {eff }}$ increase throughout the considered energy spectrum as the $\mathrm{Pb}$ content of the glasses increases; $Z_{\text {eff }}$ falls within the range of $30.74-$ $73.87,28.18-71.50,25.57-68.01,22.90-62.39,20.18-51.81$, and $17.30-30.43$ for G00 G50. The peak of $Z_{\text {eff }}$ for G50 which contains no PbO content was at the least energy (15 keV) due to photoelectric absorption cross section and its dependence on chemical content of the glass. The behavior of $Z_{\text {eff }}$ with respect to $\mathrm{E}$ is attributed to the dependence of the partial photon interaction cross sections $\left((\sigma)_{P E},(\sigma)_{C S}\right.$, and $\left.(\sigma)_{P P}\right)$ on chemical content and their variation with 
E. On the other hand, the range of $Z_{\text {eff }}$ is influenced by the range of atomic number of the atoms present in the glass system [32-34].

One practical parameter for the comparison and recommending photon shields is the half value layer (HVL). It is the thickness of the shield needed to reduce photon dose by one-half. Figure 4 shows the pictorial relationship between HVL and E of the glasses. Clearly, HVL increases in value with $\mathrm{E}$; an indication that more glass thickness is required to achieve same level of gamma radiation protection at higher energies. The figure also shows that $\mathrm{HVL}$ increases as $\mathrm{ZnO}$ content of the glasses increases relative to $\mathrm{PbO}$. At equal energy, $\mathrm{HVL}$ follows the order: (HVL) ${ }_{\mathrm{G} 00}<$ $(\mathrm{HVL})_{\mathrm{G} 10}<(\mathrm{HVL})_{\mathrm{G} 20}<(\mathrm{HVL})_{\mathrm{G} 30}<(\mathrm{HVL})_{\mathrm{G} 40}<(\mathrm{HVL})_{\mathrm{G} 50}$.

In many practical situations, the narrow beam approximation adopted for the evaluation $\mu, \mu / \rho$, $Z_{e f f}$, and HVL may not be accurate. In the broad beam approximation, transmitted photons include secondary photons generated via the interaction of primary incident photons with the attenuating medium. Such secondary photons buildup creates the error in the previously estimated parameters. Figure 5 shows the exposure buildup factor (EBF) obtained at four selected energies and for glass thickness of $0.1-1 \mathrm{~cm}$ via the GP fitting parameter procedure. The GP fitting procedure have been clearly explained in previous publication [35-37]. Across the considered energies, EBF increases with glass thickness. At low energy $(50$ and $100 \mathrm{keV})$ : $(\mathrm{EBF})_{\mathrm{G} 50}<(\mathrm{EBF})_{\mathrm{G} 40}<(\mathrm{EBF})_{\mathrm{G} 30}<(\mathrm{EBF})_{\mathrm{G} 20}$ $<(\mathrm{EBF})_{\mathrm{G} 10}<(\mathrm{EBF})_{\mathrm{G} 00 .}$. However, at higher energies, the trend is reversed. Photon buildup is proportional to absorber's thickness [35-38], CS cross section, and other photon interaction cross sections. In the low energy region, the EBF is higher for higher $Z_{e f f}$ absorber due to photoelectric process, while at higher energies, CS dictates scattering and the scattering cross section higher for 
lower $Z_{\text {eff }}$ glasses. Due to the high mass attenuation coefficient and $Z_{\text {eff }}$ value of the glasses, EBF is relatively higher at lower energies compared to the CS dominated energies.

Photon transmission $\mathrm{T}$ (in \%) calculated vis the adjusted Beer Lambert equation: $T=E B F e^{-\mu x}$ for the four photon energies are given in Figure 6. As expected, photon transmission decreases with glass thickness $(x)$ due to increasing photon interaction and absorption. At $\mathrm{E}=0.05 \mathrm{MeV}$, a thickness of $0.5 \mathrm{~cm}$ or more is enough to absorbs nearly all incident photons in all the glasses. on the other hand, a glass thickness of $0.1 \mathrm{~cm}$ reduces photon to less than $40 \%$ in all the glasses. as predicted by the photon attenuation parameters, photon transmission increases as $\mathrm{Pb}$ content of the glasses increases. Generally, the photon absorbing capacity of the glasses increases according to the order of increasing $\mathrm{PbO}$ content as observed in other glass systems involving $\mathrm{PbO}$ [39-42]. To establish the position of the present glass samples among conventional photon shields, the MFP (mean free path) of G00 and G50 were compared with those of conventional gamma radiation shields (ordinary and barite concretes, RS-360, RS-520, and RS-253-G18 glass shields; and a recently studied glass shield TVM60 [32]) at photon energies $0.015 \leq \mathrm{E} \leq 10 \mathrm{MeV}$ (Figure 7). Obviously, the present glasses have superior photon absorbing capacity compared to ordinary and barite concrete; RS-253-G18 and RS-360 commercial glass shields. although TVM60 absorbs photon better than G50, G00 however, possess a better shielding ability compared to the other shields except RS-520 whose photon shielding ability is comparable to G00 glass sample at all considered energies. The present glass (G00) thus possess tremendous photon protection capacity which is superior to many conventional ionizing radiation shields.

Neutron absorption also follows a form of Beer Lambert: $T=e^{-\Sigma_{T} x}$. The parameter $\Sigma_{T}$, represents the linear attenuation coefficient of the neutron flux incident on an absorber of thickness $x . \Sigma_{T}$ 
depends directly on atomic density and total microscopic cross section $\left(\sigma_{T}\right)$ of neutrons of certain materials in the absorber. $\Sigma_{T}$ and by extension $\sigma_{T}$ depends on the interacting nuclide and neutron energy. On the other hand, $\sigma_{T}=\sigma_{c}+\sigma_{i}+\sigma_{a}$ where the subscript $c$, $i$, and $a$ represents coherent scattering, incoherent scattering and absorption respectively. For the present glass samples, $\sigma_{c}$ and $\sigma_{a}$ have constant value for cold neutrons of energies within $0.01-2 \mathrm{meV}$ and glass thickness between 0.1 and $1 \mathrm{~cm}$ for each glass. However, $\sigma_{i}$ changes in value with respect to neutron energy but remain unchanged with thickness. The variation of $\sigma_{c}$ and $\sigma_{a}$ with to glass sample is displayed on Figure 8a. The differences in the chemical content of the glasses as it affects the atomic densities of each of the atomic species contained in the glasses is responsible for this observation. The gradual reduction/increase of $\mathrm{Pb} / \mathrm{Zn}$ in the glasses increase/decreases $\sigma_{c}$ and $\sigma_{a}$ of the neutron in the glasses. The moderation of neutrons depends mostly on $\sigma_{i}$ and hence atomic density of the glasses. As the neutron energy grows, $\sigma_{i}$ drops as shown in Figure $8 \mathrm{~b}$ in all the glasses. The changes in the atomic density of the glasses due to differences in glass chemical composition is responsible for the trend of $\sigma_{i}$ and total cross section, $\sigma_{T}$ (Figure 9) at a particular neutron energy. $\sigma_{T}$ is higher for glasses with higher $\mathrm{ZnO}$ content due to the higher $\sigma_{T}$ of $\mathrm{Zn}+\mathrm{O}$ compared to $\mathrm{Pb}$ and Ge. Hence, neutron transmission increases with energy and glass composition as predicted by $\sigma_{T}$ as shown in Figure 10. Since transmission $\propto 1 / \sigma_{T}$, G50 thus show the best potential for neutron absorption among the glasses and neutron included in the study. This is further buttressed by Figure 11 which shows the variation of MFP of neutrons with respect to glass composition and neutron energy. Obviously, glasses with higher transmission value at a particular energy is required to be thicker to provide the same level of neutron attenuation. Figure 12 depicts the effect of glass thickness on neutron transmission for glass thicknesses between $0.1-1 \mathrm{~cm}$ and selected neutron 
energies. increase in glass thickness increase the atomic density and $\Sigma_{T}$ which results in high absorption and low transmission. Based on the presented data, neutron absorbing capacity in the glasses follows the trend: G50 > G40 > G40 > G30> G20>G10> G00.

\section{Conclusion}

This work reported on the effects of reducing $\mathrm{PbO}$ content on the elastic and radiation shielding properties of germanate glasses described by the chemical formula $50 \mathrm{GeO}_{2}-(50-\mathrm{x}) \mathrm{PbO}-\mathrm{xZnO}$, where $\mathrm{x}$ between 0 and $50 \mathrm{~mol} \%$ with step of 10 . A MM-theory was employed to obtain the elastic moduli of the studied glass specimens. Moreover, the Monte Carlo simulations were applied via Geant4 platform to assess the radiation shielding ability of the $\mathrm{GeO}_{2}-\mathrm{PbO}-\mathrm{ZnO}$ glass system. With reducing $\mathrm{PbO}$ content from $50 \mathrm{~mol} \%$ to 0 , we found that the molar volume decreased from 30.129 to 20.575 , and all of $\mathrm{E}_{\mathrm{th}}, \mathrm{K}_{\mathrm{th}}, \mathrm{S}_{\mathrm{th}}$, and $\mathrm{L}_{\mathrm{th}}$ increased from 101.857 to 149.797 , from 50.751 to 85.389, from 46.865 to 66.351 , and from 113.238 to 173.857 for $E_{t h}, K_{t h}, S_{t h}$, and $L_{t h}$, respectively. The value of $\mathrm{Z}_{\mathrm{eff}}$ increases throughout the considered energy spectrum as the $\mathrm{Pb}$ content of the glasses increases; $Z_{\mathrm{eff}}$ falls within the range of $30.74-73.87,28.18-71.50,25.57-68.01,22.90-62.39$, 20.18 - 51.81, and 17.30 - 30.43 for G00 - G50. Comparing the attenuation capacity of the glasses for gamma rays and neutrons, it is clear that the glass composition strongly influenced the ability of a glass for shielding purposes. The optimum composition which gives the best neutron absorption produced the worst gamma ray shielding efficacy. However, analyzed data proved that the glass system can be used as an effective photon and neutron shields.

\section{Acknowledgments}


The authors thank the Deanship of Scientific Research at King Khalid University for financial support under grant number (R.G.P.1/237/42).

\section{References}

1. Mattsson, Sören. "Introduction: The Importance of Radiation Protection in Nuclear Medicine." In Radiation Protection in Nuclear Medicine, pp. 1-3. Springer, Berlin, Heidelberg, 2013.

2. Weingart, Steve H. "Physical security devices for computer subsystems: A survey of attacks and defenses." In International Workshop on Cryptographic Hardware and Embedded Systems, pp. 302-317. Springer, Berlin, Heidelberg, 2000.

3. National Research Council. "Health risks from exposure to low levels of ionizing radiation: BEIR VII phase 2." (2006).

4. Preston, R. Julian, John D. Boice Jr, A. Bertrand Brill, Ranajit Chakraborty, Rory Conolly, F. Owen Hoffman, Richard W. Hornung et al. "Uncertainties in estimating health risks associated with exposure to ionising radiation." Journal of radiological protection 33, no. 3 (2013): 573.

5. Krille, Lucian, Gaël P. Hammer, Hiltrud Merzenich, and Hajo Zeeb. "Systematic review on physician's knowledge about radiation doses and radiation risks of computed tomography." European journal of radiology 76, no. 1 (2010): 36-41.

6. Chilton, Arthur B., J. Kenneth Shultis, and Richard E. Faw. "Principles of radiation shielding." (1984). 
7. Price, Benjamin Terence, Clifford C. Horton, and Kenneth Thomas Spinney. Radiation shielding. Pergamon press, 1957.

8. McCaffrey, J. P., H. Shen, B. Downton, and E. Mainegra-Hing. "Radiation attenuation by lead and nonlead materials used in radiation shielding garments." Medical physics 34, no. 2 (2007): 530-537.

9. Divina, R., Naseer, K.A., Marimuthu, K. et al. (2020). Effect of different modifier oxides on the synthesis, structural, optical, and gamma/beta shielding properties of bismuth lead borate glasses doped with europium. J Mater Sci: Mater Electron 31, 21486-21501 https://doi.org/10.1007/s10854-020-04662-3

10. Al-Buriahi, M. S., H. H. Hegazy, Faisal Alresheedi, I. O. Olarinoye, H. Algarni, H. O. Tekin, and H. A. Saudi. (2020).Effect of CdO addition on photon, electron, and neutron attenuation properties of boro-tellurite glasses. Ceramics International https://doi.org/10.1016/j.ceramint.2020.10.168

11. Lakshminarayana, G., Ashok Kumar, H. O. Tekin, Shams AM Issa, M. S. Al-Buriahi, Dong-Eun Lee, Jonghun Yoon, and Taejoon Park. (2020)Binary B2O3-Bi2O3 glasses: scrutinization of directly and indirectly ionizing radiations shielding abilities. Journal of Materials Research and Technology 9, no. 6: 14549-14567. https://doi.org/10.1016/j.jmrt.2020.10.019

12. Tchounwou, Paul B., Clement G. Yedjou, Anita K. Patlolla, and Dwayne J. Sutton. "Heavy metal toxicity and the environment." Molecular, clinical and environmental toxicology (2012): 133-164. 
13. Naja, Ghinwa M., and Bohumil Volesky. "Toxicity and sources of $\mathrm{Pb}, \mathrm{Cd}, \mathrm{Hg}, \mathrm{Cr}$, As, and radionuclides in the environment." Heavy metals in the environment 8 (2009): 16-18.

14. Sharma, Pallavi, and Rama Shanker Dubey. "Lead toxicity in plants." Brazilian journal of plant physiology 17, no. 1 (2005): 35-52.

15. Stalin, Salavadi, D. K. Gaikwad, M. S. Al-Buriahi, Ch Srinivasu, Shaik Amer Ahmed, H. O. Tekin, and Syed Rahman. "Influence of Bi2O3/WO3 substitution on the optical, mechanical, chemical durability and gamma ray shielding properties of lithium-borate glasses." Ceramics International 47, no. 4 (2021): 5286-5299.

16. Boukhris, Imed, Imen Kebaili, M. S. Al-Buriahi, Chahkrit Sriwunkum, and M. I. Sayyed. "Effect of lead oxide on the optical properties and radiation shielding efficiency of antimony-sodium-tungsten glasses." Applied Physics A 126, no. 10 (2020): 1-10.

17. Olarinoye, I. O., Y. S. Rammah, Shoroog Alraddadi, Chahkrit Sriwunkum, A. F. Abd ElRehim, H. Y. Zahran, and M. S. Al-Buriahi. "The effects of La2O3 addition on mechanical and nuclear shielding properties for zinc borate glasses using Monte Carlo simulation." Ceramics International 46, no. 18 (2020): 29191-29198.

18. Guedes, Luis Felipe Nascimento, Lia Mara Marcondes, Renato Oliveira Evangelista, Gislene Batista, Valentina Gacha Mendoza, Fabia Castro Cassanjes, and Gael Yves Poirier. "Effect of alkaline modifiers on the structural, optical and crystallization properties of niobium germanate glasses and glass-ceramics." Optical Materials 105 (2020): 109866. 
19. Koroleva, Olga N., Mikhail V. Shtenberg, and Tatyana N. Ivanova. "The structure of potassium germanate glasses as revealed by Raman and IR spectroscopy." Journal of NonCrystalline Solids 510 (2019): 143-150.

20. Rada, Simona, R. Chelcea, M. Rada, A. Bot, N. Aldea, V. Rednic, and E. Culea. "Electrochemical characterization and structure of tungsten-lead-germanate glasses and glass ceramics." Electrochimica Acta 109 (2013): 82-88.

21. Bayya, Shyam S., Geoffrey D. Chin, Jasbinder S. Sanghera, and Ishwar D. Aggarwal. "Germanate glass as a window for high energy laser systems." Optics Express 14, no. 24 (2006): 11687-11693.

22. Trukhin, A., and B. Capoen. "Raman and optical reflection spectra of germanate and silicate glasses." Journal of non-crystalline solids 351, no. 46-48 (2005): 3640-3643.

23. Mansour, E., G. El-Damrawi, R. E. Fetoh, and H. Doweidar. "Structure-properties changes in ZnO-PbO-GeO 2 glasses." The European Physical Journal B 83, no. 2 (2011): 133-141.

24. Agostinelli, Sea, John Allison, K. al Amako, John Apostolakis, H. Araujo, P. Arce, M. Asai et al. "GEANT4 — a simulation toolkit." Nuclear instruments and methods in physics research section A: Accelerators, Spectrometers, Detectors and Associated Equipment 506, no. 3 (2003): 250-303.

25. Makishima, A., \& Mackenzie, J. D. (1973). Direct calculation of Young's moidulus of glass. Journal of Non-Crystalline Solids, 12(1), 35-45. 
26. Makishima, A., \& Mackenzie, J. D. (1975). Calculation of bulk modulus, shear modulus and Poisson's ratio of glass. Journal of Non-crystalline solids, 17(2), 147-157.

27. Abd El-Moneim, Amin, and H. Y. Alfifi. "Germanate glasses containing lead and bismuth oxides: Correlation between elastic and compositional parameters." Journal of NonCrystalline Solids 546 (2020): 120275.

28. Abd El-Moneim, Amin. "Elastic moduli and Poisson's ratio prediction in borate-based PbO-B2O3-V2O5 and Li2O-ZnO-B2O3 glass systems." Journal of Non-Crystalline Solids 514 (2019): 69-76.

29. Abd El-Moneim, A., \& El-Mallawany, R. (2019). Analysis and prediction for elastic properties of quaternary tellurite $\mathrm{Ag} 2 \mathrm{O}-\mathrm{V} 2 \mathrm{O} 5-\mathrm{MoO} 3-\mathrm{TeO} 2$ and $\mathrm{WO} 3-\mathrm{B} 2 \mathrm{O} 3-\mathrm{MgO}-$ TeO2 glasses. Journal of Non-Crystalline Solids, 522, 119580.

30. Şakar, E., Özpolat, Ö. F., Alım, B., Sayyed, M. I., \& Kurudirek, M. (2020). Phy-X/PSD: development of a user friendly online software for calculation of parameters relevant to radiation shielding and dosimetry. Radiation Physics and Chemistry, 166, 108496.

31. S.S. Mann, K.S. Mann (2020). "RIPM-Toolkit: a computer program to investigate doublelayered gamma-ray shielding enclosures." Computational methods in nuclear radiation shielding and dosimetry, Edited by K.S. Mann, and V.P. Singh, Nova Science Publishers, New York, $1-30$.

32. I.O. Olarinoye, F.I. El-Agawany, A. El-Adawy, El Sayed Yousef, Y.S. Rammah, Mechanical features, alpha particles, photon, proton, and neutron interaction parameters of 
TeO2-V2O3-MoO3 semiconductor glasses, Ceramics International, Volume 46, Issue 14, 2020, 23134-23144.

33. Hine G.J., The effective atomic numbers of materials for various gamma ray interactions, Phys. Rev., 85, 725 (1952).

34. Olarinoye, I.O. (2011). Variation of Effective Atomic Numbers of Some Thermoluminescence and Phantom Materials with Photon Energies. Research Journal of Chemical Science 1(2). 64-69.

35. I.O. Olarinoye (2020). "Ambient dose buildup factor." Computational methods in nuclear radiation shielding and dosimetry, Edited by K.S. Mann, and V.P. Singh, Nova Science Publishers, New York, 87 - 112.

36. Olarinoye, I. O., Odiaga, R. I., \& Paul, S. (2019). EXABCal: A program for calculating photon exposure and energy absorption buildup factors. Heliyon, 5(7), e02017.

37. Y. Harima, An approximation of gamma-ray buildup factors by modified geometrical progression, Nucl. Sci. Eng. 83 (1983) 299-309, https://doi.org/10.13182/NSE83-A18222.

38. Basu, P., Sarangapani, R., \& Venkatraman, B. (2019). Gamma ray buildup factors for conventional shielding materials and buildup factors computed for tungsten with a thickness beyond 40 mean free paths. Applied Radiation and Isotopes, 154, 108864.

39. Perişanoğlu, U., El-Agawany, F. I., Kavaz, E., Al-Buriahi, M., \& Rammah, Y. S. (2020). Surveying of Na2O3- $\mathrm{BaO}-\mathrm{PbO}-\mathrm{Nb} 2 \mathrm{O} 5-\mathrm{SiO} 2-\mathrm{A} 12 \mathrm{O} 3$ glass-ceramics system in terms of 
alpha, proton, neutron and gamma protection features by utilizing GEANT4 simulation codes. Ceramics International, 46(3), 3190-3202.

40. Aly, P., El-Kheshen, A. A., Abou-Gabal, H., \& Agamy, S. (2020). Structural investigation and measurement of the shielding effect of borosilicate glass containing $\mathrm{PbO}, \mathrm{SrO}$, and $\mathrm{BaO}$ against gamma irradiation. Journal of Physics and Chemistry of Solids, 109521.

41. Y.S. Rammah, I.O. Olarinoye, F.I. El-Agawany, A. El-Adawy, El Sayed Yousef. The ffactor, neutron, gamma radiation and proton shielding competences of glasses with $\mathrm{Pb}$ or $\mathrm{Pb} / \mathrm{Bi}$ heavy elements for nuclear protection applications, Ceramics International, Volume 46, Issue 17, 2020, 27163-27174.

42. Amani Alalawi, M.S. Al-Buriahi, M.I. Sayyed, H. Akyildirim, H. Arslan, M.H.M. Zaid, B.T. Tonguc, Influence of lead and zinc oxides on the radiation shielding properties of tellurite glass systems, Ceram. Int. 46 (Aug 2020) 17300-17306, https://doi.org/10.1016/j.ceramint.2020.04.017. 


\section{Figures}

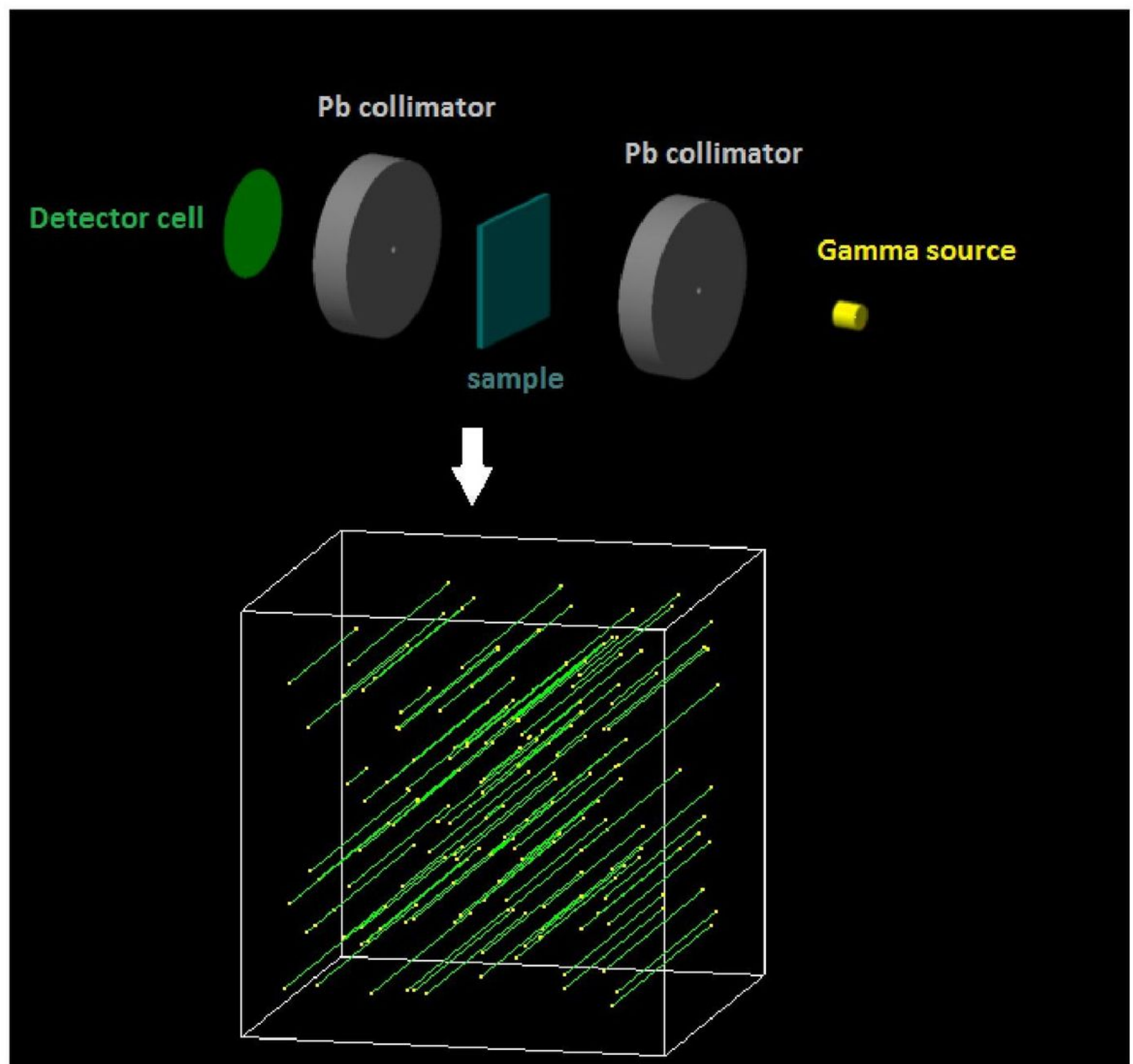

\section{Figure 1}

3D view for the simulation procedures including schematic representation of the narrow beam transmission geometry and cross sectional view showing 100 gamma photons passing through the glass sample. 


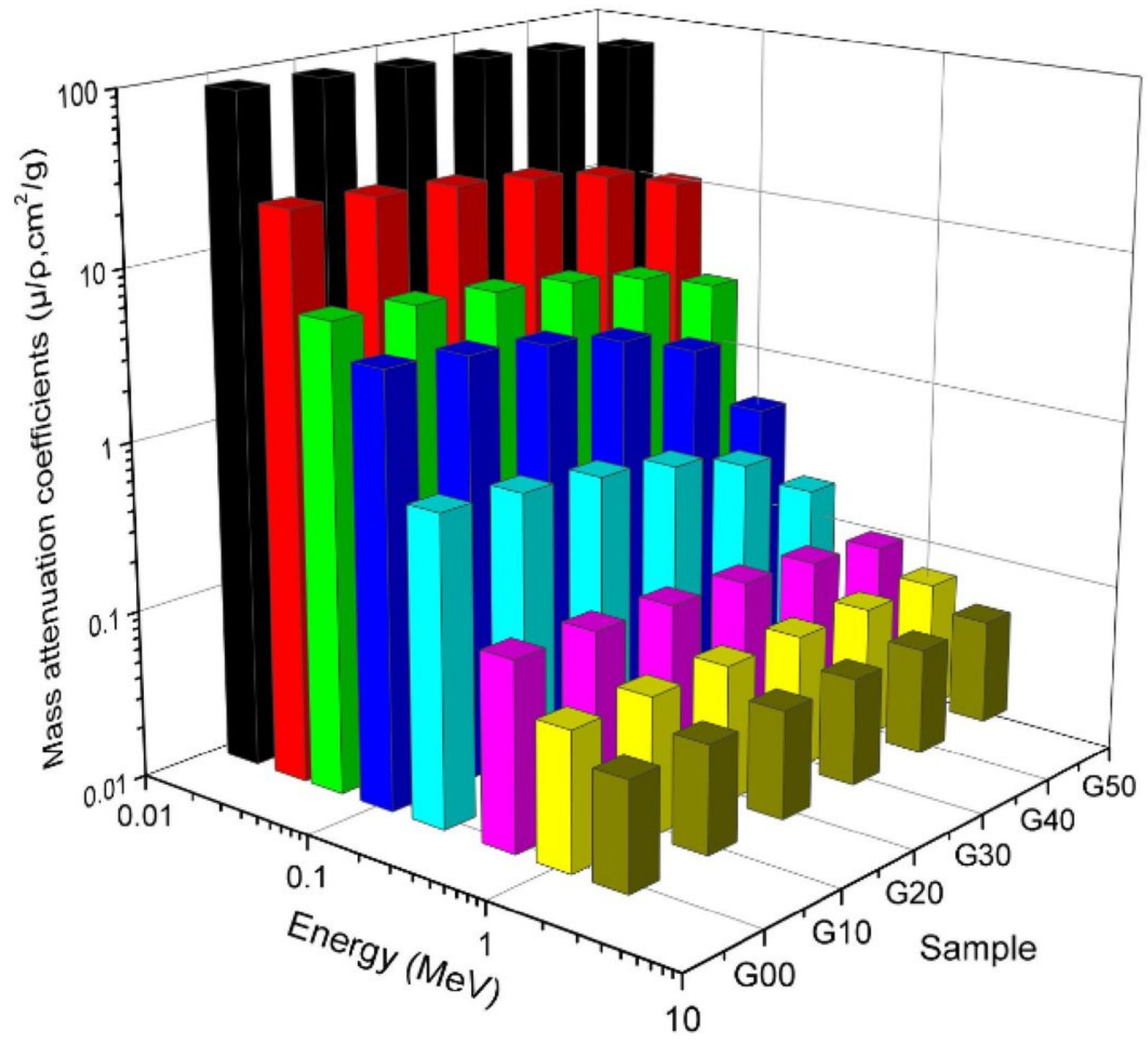

Figure 2

Mass attenuation coefficient of G00 - G50 glasses at different photon energy in MeV. 


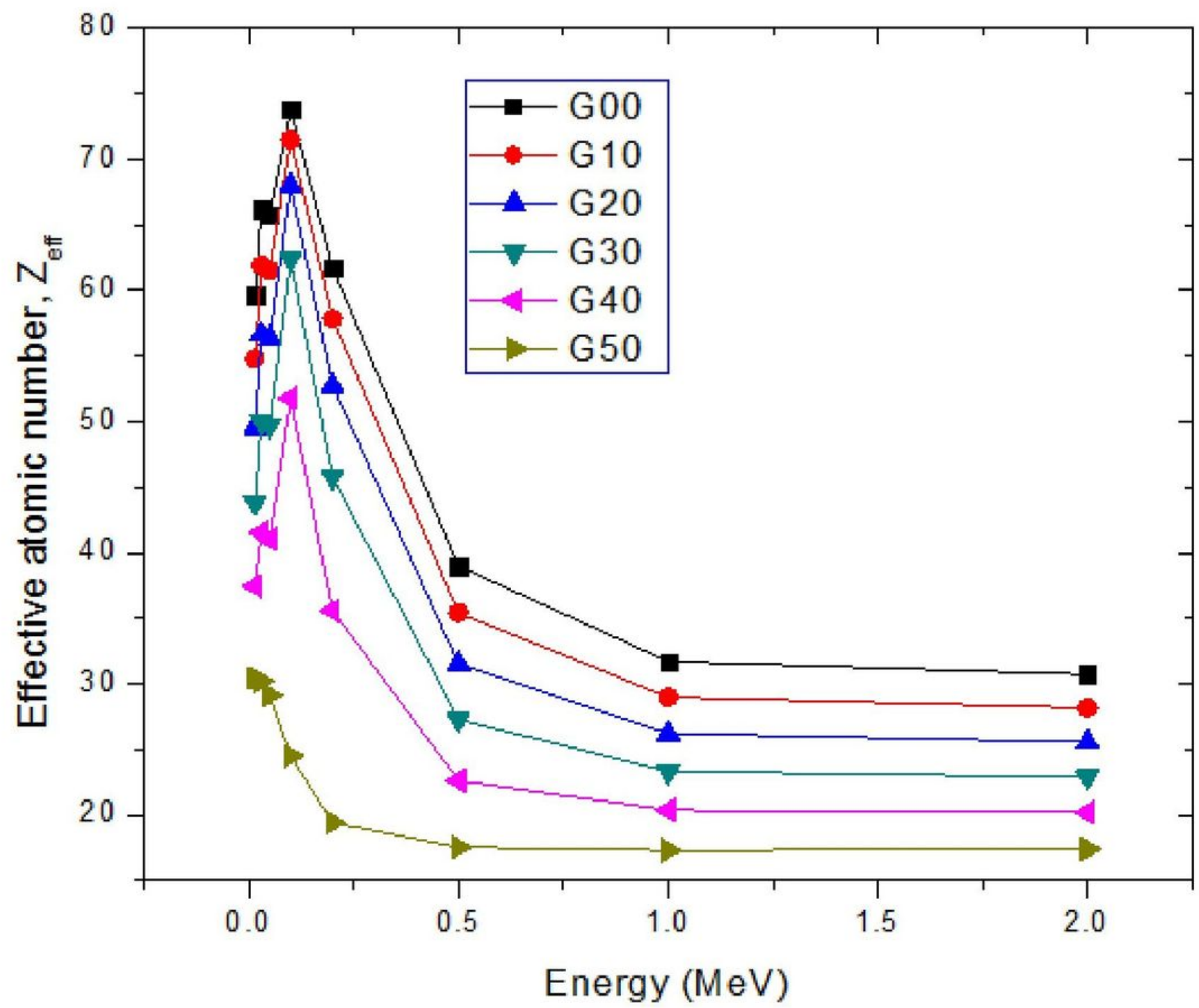

Figure 3

Effective atomic number of the glasses as functions of photon energy. 


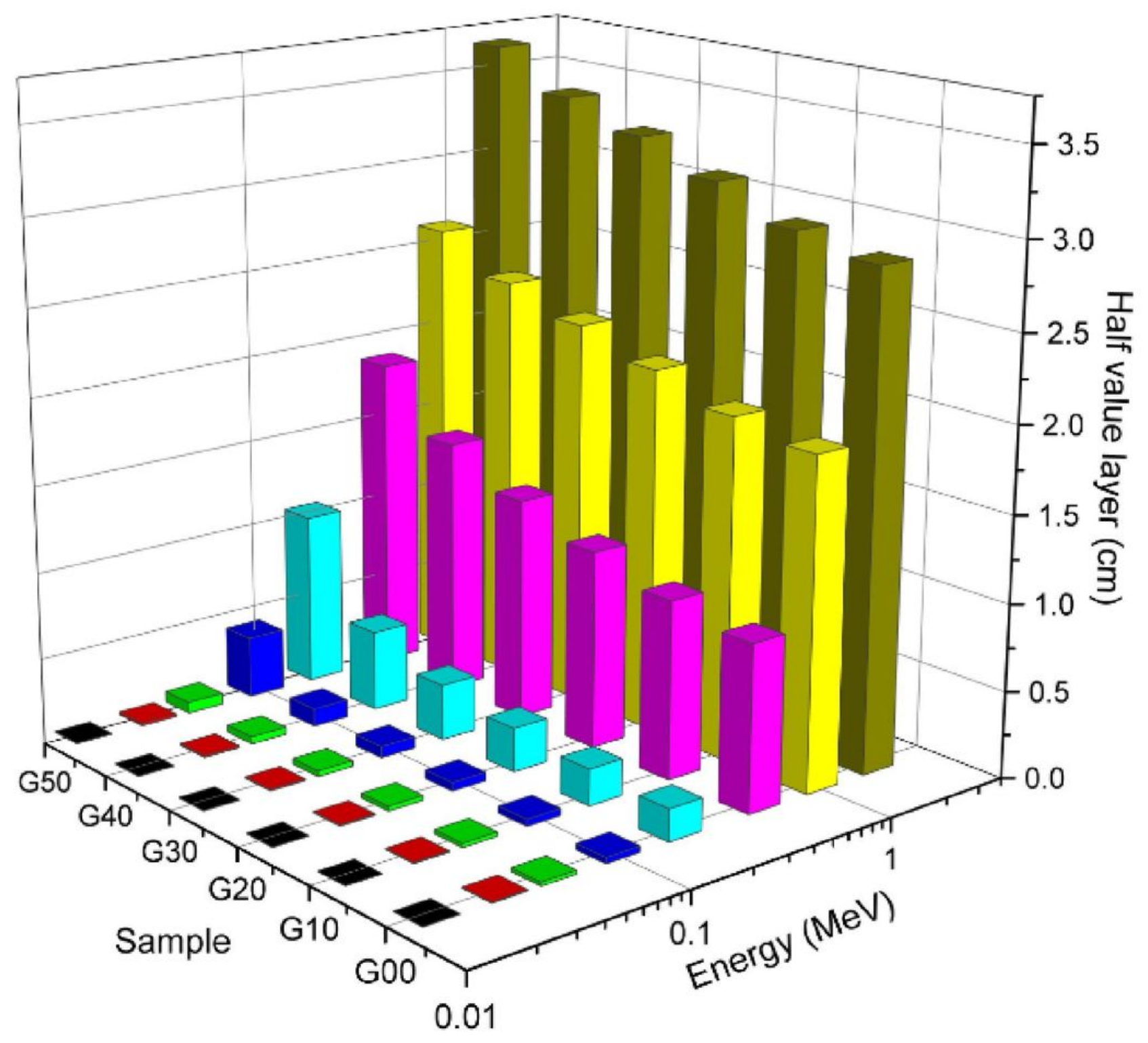

Figure 4

Half value layer of G00 - G50 at different energies. 

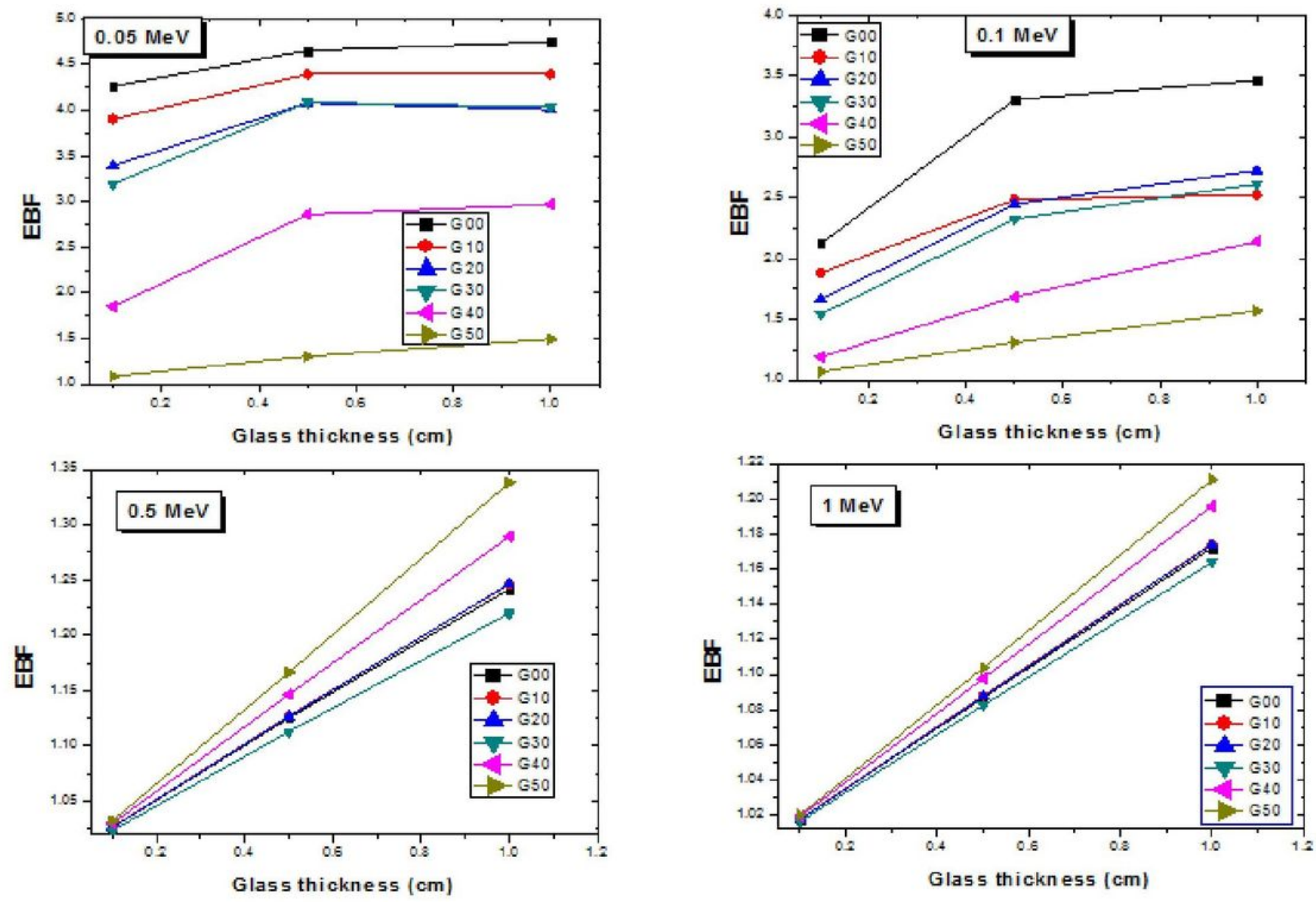

Figure 5

Exposure buildup factor as function of glass thickness. 

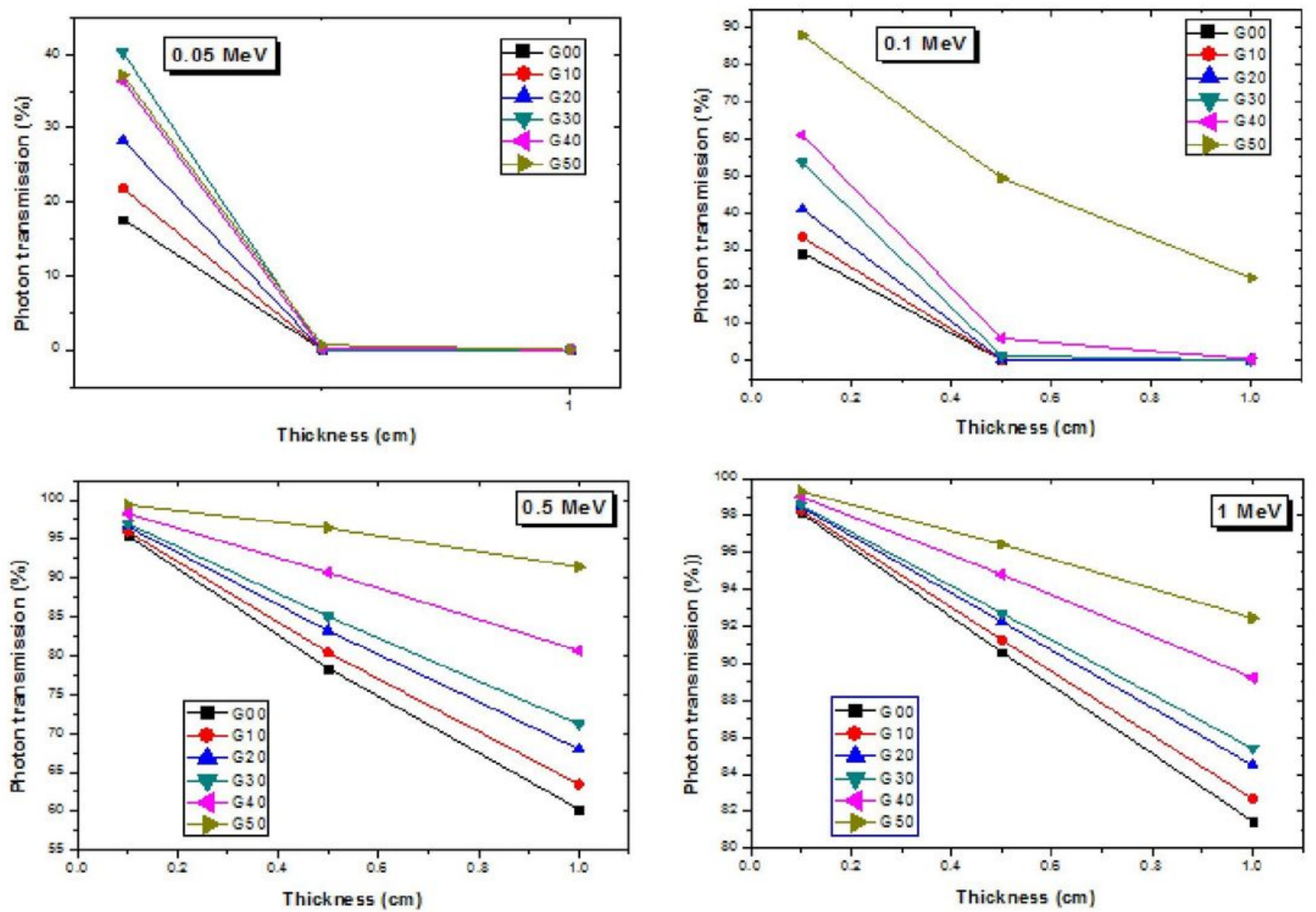

\section{Figure 6}

Photon transmission at selected energies and thicknesses. 


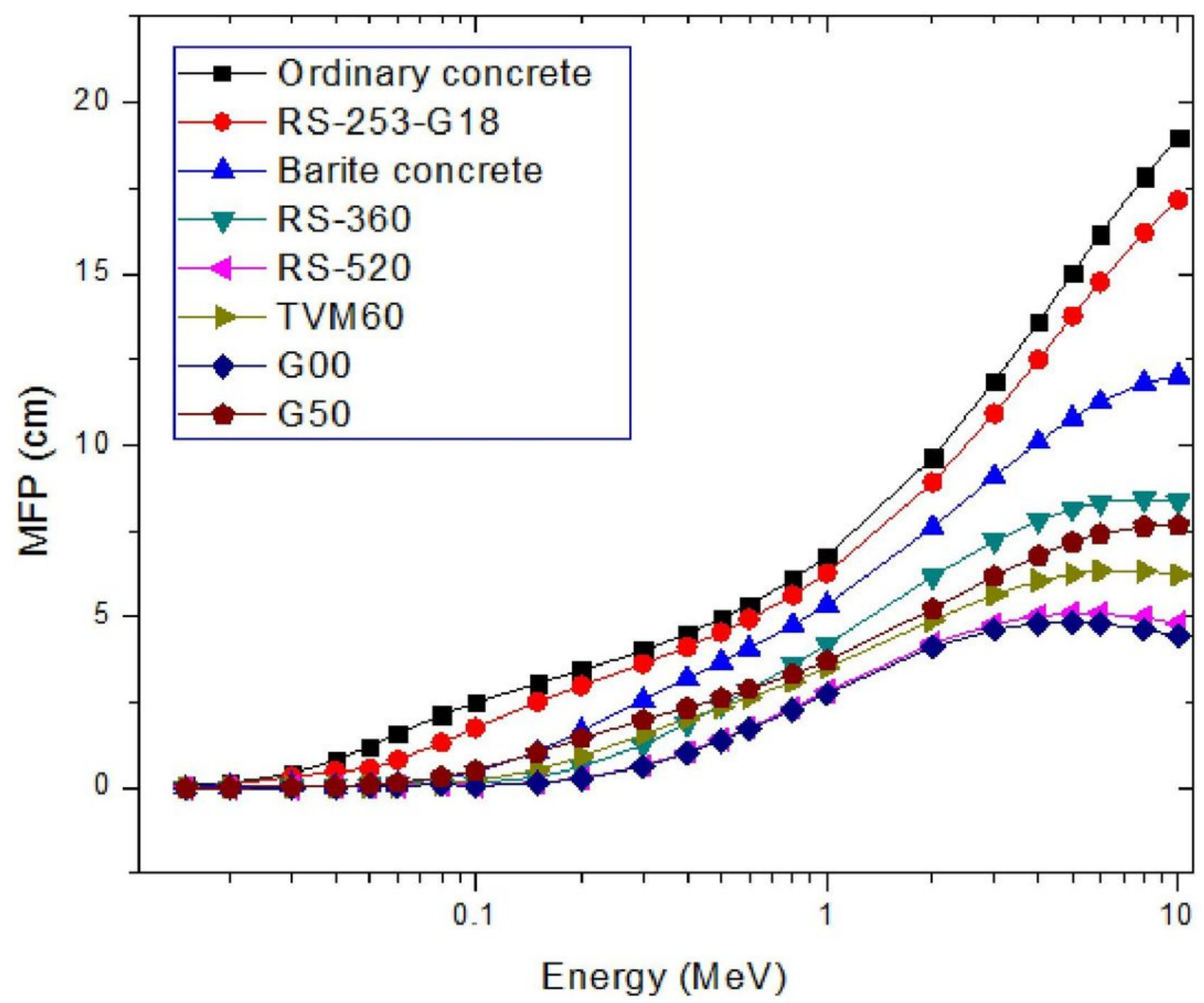

Figure 7

Comparison of photon shielding ability of the glasses with those of other conventional shields. 

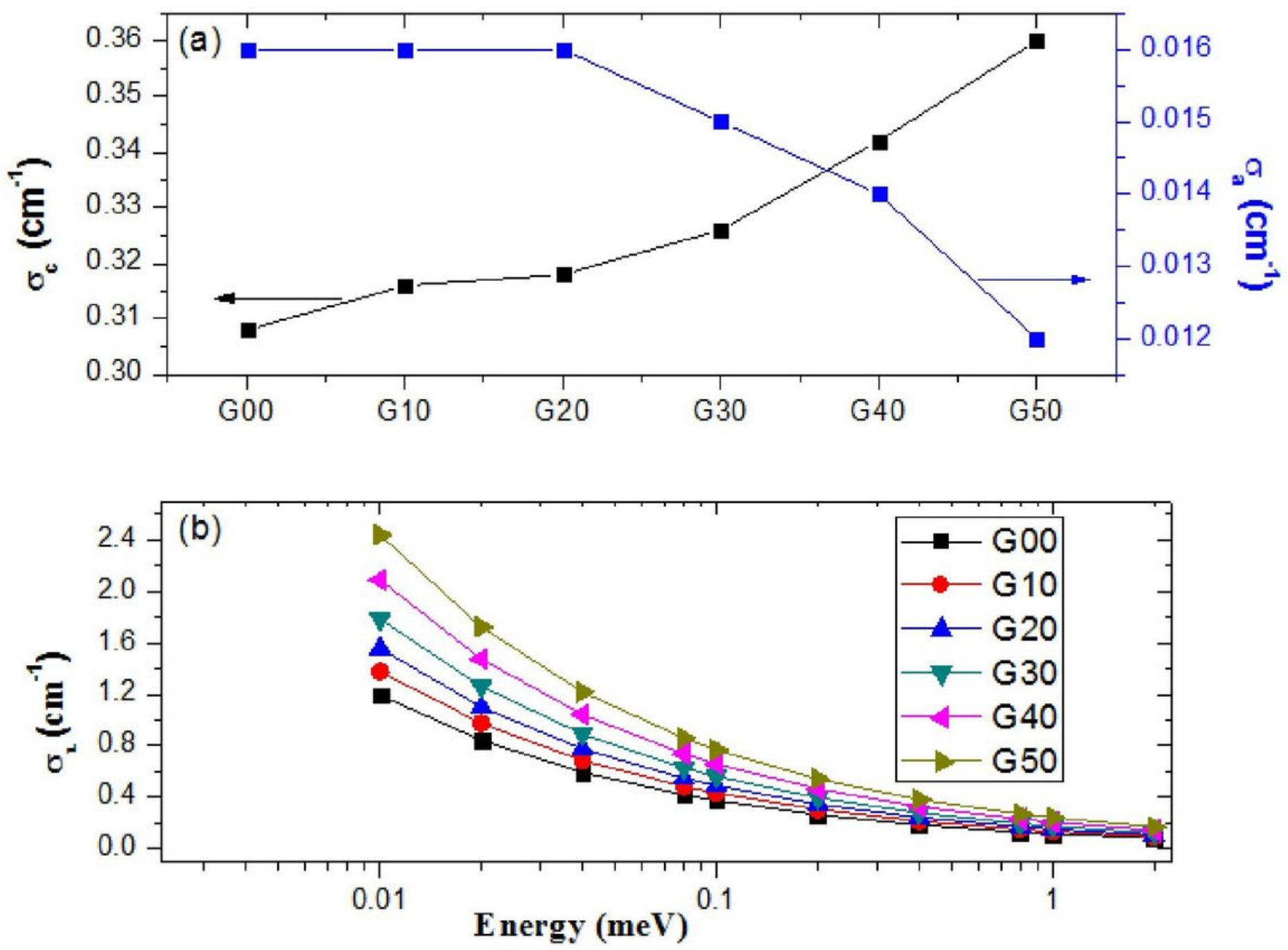

Figure 8

Varaiation of $\sigma c$ and $\sigma a$ with glass sample (a) and $\sigma i$ changes with neutron energy. 


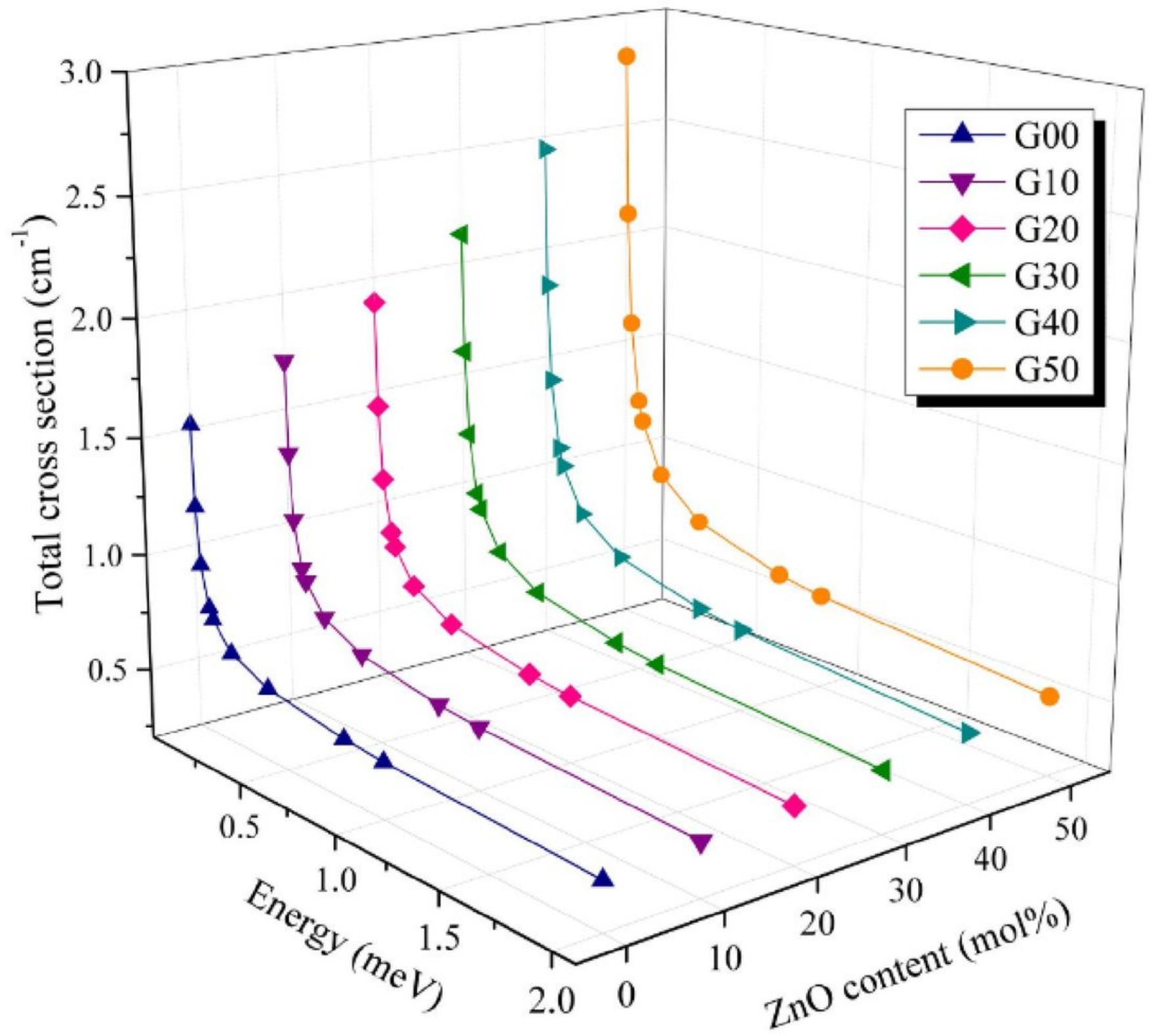

Figure 9

Neutron total cross section as a function neutron energy and $\mathrm{ZnO}$ of the glasses. 


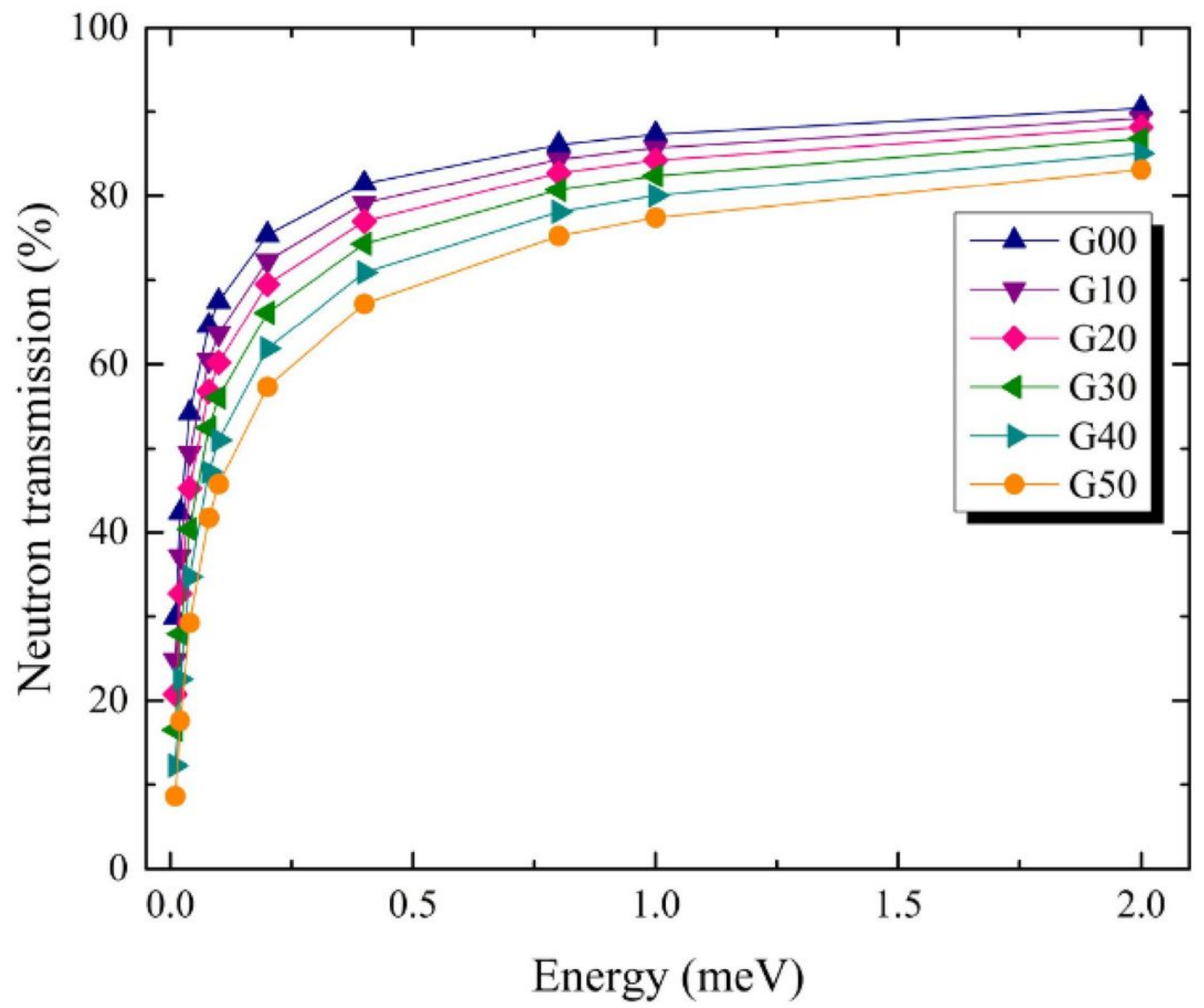

Figure 10

Neutron transmission through the glasses as function of energy. 


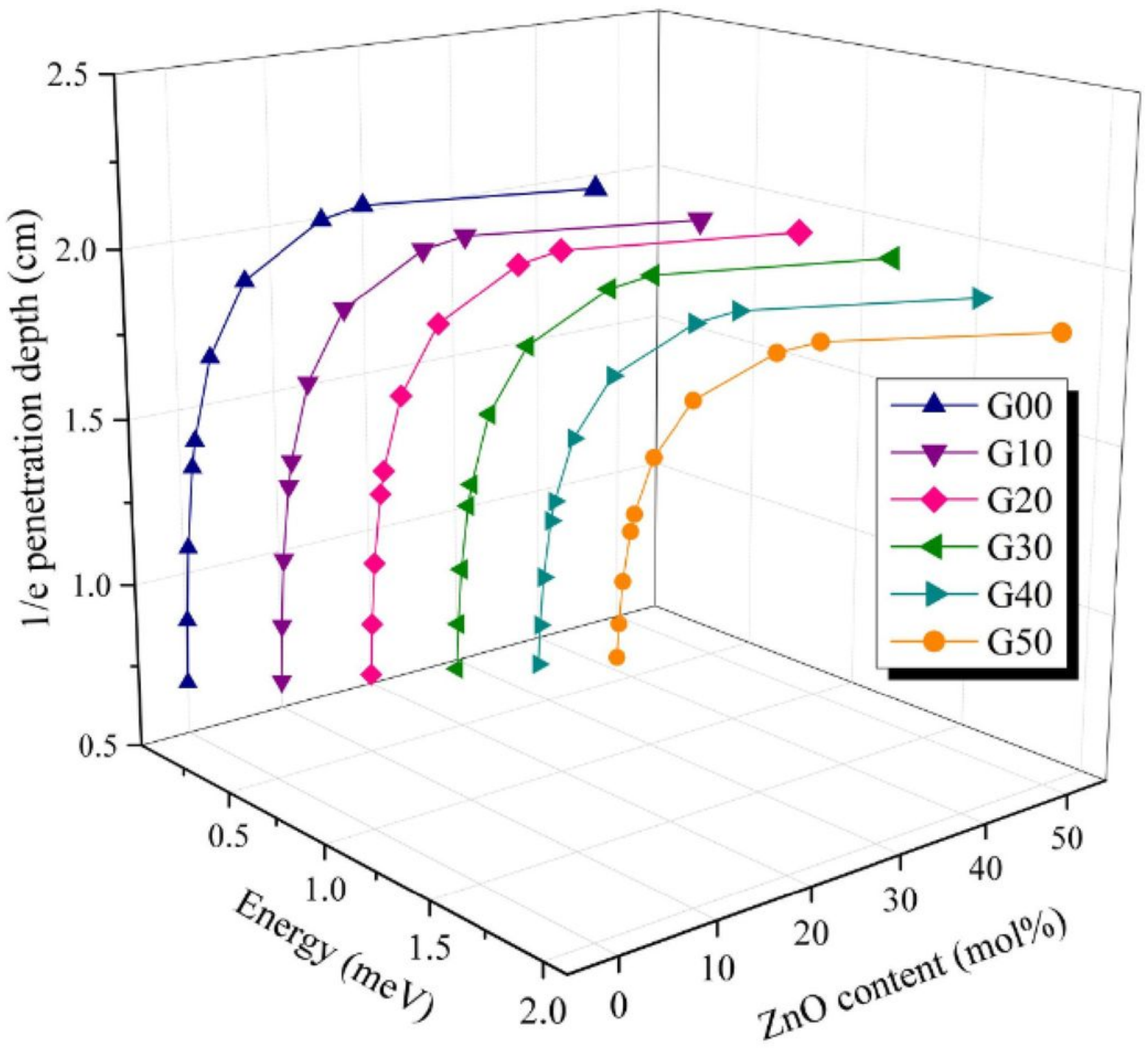

Figure 11

Variation of MFP of neutrons with respect to glass composition and neutron energy. 

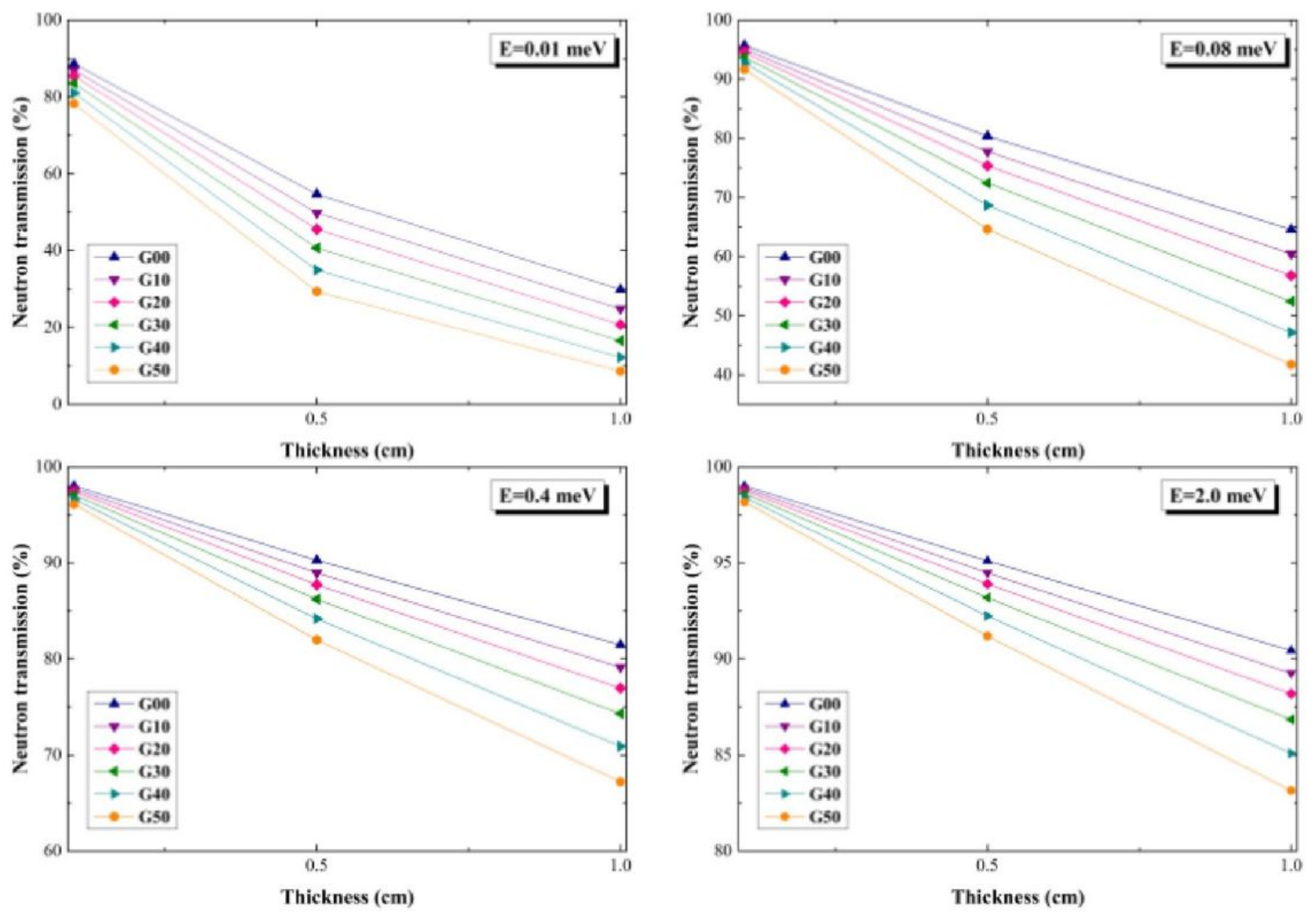

Figure 12

The effect of glass thickness on neutron transmission at selected energies. 